\title{
Aplysiasecosterol A: A 9,11-Secosteroid with an Unprecedented Tricyclic $\gamma$-Diketone Structure from the Sea Hare
} Aplysia kurodai **

\author{
Atsushi Kawamura, Masaki Kita,* and Hideo Kigoshi*
}

\begin{abstract}
A new 9,11-secosteroid having an unprecedented tricyclic $\gamma$-diketone structure, aplysiasecosterol A (1), was isolated from the sea hare Aplysia kurodai. The structure was determined by 1D and 2D NMR spectroscopic analysis, molecular modeling studies, a comparison of experimental and calculated ECD spectra, and a modified Mosher's method. Aplysiasecosterol A (1) exhibited cytotoxicity against human myelocytic leukemia HL-60 cells. A biosynthetic pathway for $\mathbf{1}$ from a cholesterol was proposed, which includes twice $\alpha$-ketol rearrangement and an intramolecular acetalization.
\end{abstract}

Sea hares (family Aplysiidae) belong to the opisthobranch group of mollusks (clade Aplysiomorpha). ${ }^{[1]}$ They are shell-less and benthic marine invertebrates, and have been postulated to contain chemical defense substances. Among them, the genera Aplysia and Dolabella are known to be rich sources of bioactive molecules. ${ }^{[2]}$ For example, dolastatin 10 is an antineoplastic peptide that was obtained from the Indian Ocean sea hare Dolabella sp. ${ }^{[3]}$ In 2011, an mAb-targeted dolastatin 10 conjugate was approved for the treatment of Hodgkin's lymphoma. Aplyronine A, a highly potent antitumor and actindepolymerizing macrolide, was isolated from the Japanese sea hare Aplysia kurodai. ${ }^{[4]}$ Recently, aplyronine A was shown to induce protein-protein interaction between actin and tubulin and to prevent spindle formation and mitosis. ${ }^{[5]}$ In addition, various secondary metabolites have been isolated from $A$. kurodai, including the shikimate derivatives pericosines, ${ }^{[6]}$ the sterol derivatives aplykurodins, ${ }^{[7]}$ and the alkaloids gliocladins ${ }^{[8]}$ and aplaminal. ${ }^{[9]}$ These molecules are expected to give new insights for the discovery and development of a new class of pharmacological tools and therapeutic agents.

In our continuing search for new bioactive compounds from A. kurodai, aplysiasecosterol A (1), a 9,11-secosteroid having an unprecedented tricyclic $\gamma$-diketone structure, was isolated. We report here the isolation, structure determination, and bioactivity of 1 .

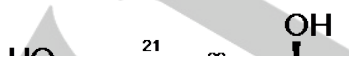

[*] A. Kawamura, Prof. Dr. M. Kita, Prof. Dr. H. Kigoshi

Graduate School of Pure and Applied Sciences

University of Tsukuba

1-1-1 Tennodai, Tsukuba 305-8571 (Japan)

Fax: (+81) 29-853-4313

E-mail:mkita@chem.tsukuba.ac.jp; kigoshi@chem.tsukuba.ac.jp

[**] This work is supported in part by JSPS grants (25702047 to M.K. and 26242073 to H.K.) and by a Grant-in-Aid for Scientific Research on Innovative Areas from MEXT, Japan, "Chemical Biology of Natural Products." Support was also provided by the Naito Foundation, the Uehara Memorial Foundation, and the Takeda Science Foundation.

Supporting information for this article is available on the WWW under http://dx.doi.org/10.1002/anie??
The sea hare A. kurodai (54.8 kg, wet wt.) was extracted with aqueous ethanol. The concentrated extract was partitioned between ethyl acetate and water. The ethyl acetate layer was further partitioned with $n$-hexane, dichloromethane, and $60 \%$ aqueous methanol. Apart from the highly cytotoxic fractions that contain aplyronines, we investigated the other constituents in the dichloromethane layer. Repeated $\mathrm{SiO}_{2}, \mathrm{Al}_{2} \mathrm{O}_{3}$, and ODS column chromatography and final reverse-phase HPLC purification afforded aplysiasecosterol $A(1)$ as a colorless oil $\{6.7 \mathrm{mg}$, $\left.1.2 \times 10^{-7} \%,[\alpha]^{24}+19.3(c \quad 0.228, \mathrm{MeOH})\right\}$. Aplysiasecosterol A (1) did not show significant cytotoxicity against the human cervical carcinoma cell line HeLa S3 at $200 \mu \mathrm{M}$, while it exhibited moderate cytotoxicity against the human myelomonocytic leukemia cell line $\mathrm{HL}-60\left(\mathrm{IC}_{50}=16 \mu \mathrm{M}\right)$.

The molecular formula of 1 was established to be $\mathrm{C}_{27} \mathrm{H}_{44} \mathrm{O}_{7}$ by HR-ESIMS ([M+Na $]^{+}, \mathrm{m} / \mathrm{z}$ 503.2979, $\left.\Delta-0.6 \mathrm{mmu}\right)$. The planar structure of 1 was determined by $1 \mathrm{D}$ and 2D NMR analysis (Figure 1). The ${ }^{1} \mathrm{H},{ }^{13} \mathrm{C}$ NMR, DEPT135 and HSQC spectra in $\mathrm{CDCl}_{3}$ showed that 1 had four singlet methyl groups $\left(\delta_{\mathrm{H}} 0.89\right.$, $1.11,1.21,1.15)$, one doublet methyl group $\left(\delta_{\mathrm{H}} 0.92\right)$, two carbonyl carbons $\left(\delta_{\mathrm{c}} 208.28,216.50\right)$, and one acetal carbon $\left(\delta_{\mathrm{c}}\right.$ 101.31). The IR $\left(\mathrm{CHCl}_{3}\right)$ spectrum of 1 showed absorption bands for hydroxyl groups $\left(3568 \mathrm{~cm}^{-1}\right)$ and two carbonyl groups (1736, $\left.1708 \mathrm{~cm}^{-1}\right)$.

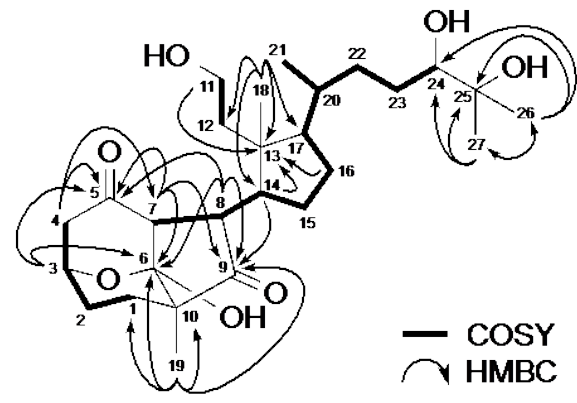

Figure 1. Planar structure of aplysiasecosterol A (1) determined by 2D-NMR analysis (bold line, COSY; arrows, selected HMBC correlations).

A detailed analysis of the COSY spectrum of 1 allowed us to construct three partial structures: C-1-C-4, C-7-C-24, and C11-C-12 (Figure 1, Table S1). HMBC correlations between Me18/C-12, C-13, C-14 and C17 revealed that the C-7-C-24 unit was linked to the $\mathrm{C}-11-\mathrm{C}-12$ unit via the $\mathrm{sp}^{3}$ quaternary carbon C-13. Similarly, HMBC correlations between Me-19/C-1, C-6, C9, and C-10 indicated that C-1, C-6, C-9, and C-19 were each connected to the $\mathrm{sp}^{3}$ quaternary carbon $\mathrm{C}-10$. The C-8-C-9 connectivity was established based on $\mathrm{HMBC}$ correlations between $\mathrm{H}-7, \mathrm{H}-8$, and $\mathrm{H}-14 / \mathrm{C}-9$. Further $\mathrm{HMBC}$ correlations between $\mathrm{H}-7$ and $\mathrm{H}-8 / \mathrm{C}-5$ and $\mathrm{C}-6$ indicated that the carbonyl 
carbon C-5 and the acetal carbon C-6 were connected to the methine carbon $\mathrm{C}-7$. Thus, the results showed that 1 possesses a cyclopentanone moiety $\left(C-9,1736 \mathrm{~cm}^{-1}\right)$ with an acetal carbon Moreover, the presence of both a tetrahydropyran ring and a 4oxacyclohexanone moiety $\left(\mathrm{C}-5,1708 \mathrm{~cm}^{-1}\right)$ in 1 was established by $\mathrm{HMBC}$ correlations between $\mathrm{H}-3 / \mathrm{C}-5$ and $\mathrm{C}-6$ and $\mathrm{H}-4 / \mathrm{C}-5$ and $\mathrm{C}-7$. Furthermore, the connectivity of two singlet methyl groups (C-26, 27) and an 1,2-diol moiety was clarified based on HMBC correlations between Me-26/C-24, C-25, and C-27, and Me-27/C-24, C-25, and C-26. Based on the molecular formula and the degree of unsaturation, 1 was shown to contain four hydroxyl groups. Therefore, the planar structure of aplysiasecosterol A (1) was determined to be as shown in Figure 1.
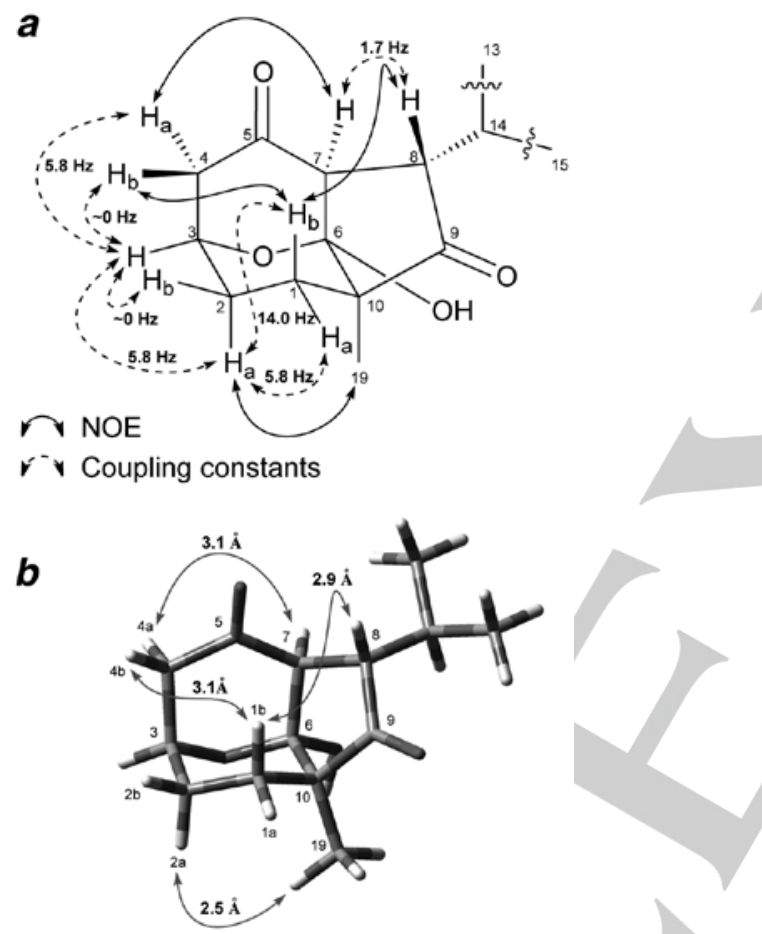

Figure 2. (a) Relative stereochemistry of the tricyclic $\gamma$-diketone structure of 1 determined by $1 \mathrm{D}$ and 2D-NMR analysis (solid arrows, selected NOE correlations; dashed arrows, coupling constants). (b) Optimized structure of the tricyclic model compound 2 at the B3LYP/6-31G+ level of theory in the gas phase. The substituent on C-8 in $\mathbf{2}$ was replaced with an isopropyl group. Solid arrows are the calculated distances between two selected protons.

Next, the relative stereochemistry of the tricyclic $\gamma$-diketone structure of 1 was established. The large magnitude of $J_{1 b, 2 a}=$ $14.0 \mathrm{~Hz}$ and the relatively small magnitudes of $J_{1 a, 2 a}=5.8 \mathrm{~Hz}$, $J_{2 a, 3}=5.8 \mathrm{~Hz}$, and $J_{2 b, 3}=c a$. $0 \mathrm{~Hz}$ suggested that $\mathrm{H}-1 \mathrm{~b}$ and $\mathrm{H}-2 \mathrm{a}$ were oriented in an anti arrangement in the tetrahydropyran ring (Figure 2a). Key NOEs were observed for $\mathrm{H}-1 \mathrm{~b} / \mathrm{H}-4 \mathrm{~b}$ and $\mathrm{H}-$ $1 \mathrm{~b} / \mathrm{H}-8$, which indicated that these three protons faced each other on the concave face of the rigid tricyclic structure. Similarly, NOE correlations for $\mathrm{H}-4 \mathrm{a} / \mathrm{H}-7$ and $\mathrm{H}-2 \mathrm{a} / \mathrm{Me}-19$ suggested that all of the protons $\mathrm{H}-2 \mathrm{a}, \mathrm{H}-4 \mathrm{a}, \mathrm{H}-7$, and Me-19 were located in the convex face. Thus, $\mathrm{H}-1 \mathrm{~b}, \mathrm{H}-2 \mathrm{a}$ and $\mathrm{Me}-19$ were thought to be oriented in an axial position with respect to the tetrahydropyran ring with a chair conformation.

A molecular modeling study using a Merck molecular force field 94x (MMFF94x) showed that the tricyclic $\gamma$-diketone model compound 2, in which the substituent on C-8 was replaced with an isopropyl group, had only one conformer within $7 \mathrm{kcal} / \mathrm{mol}$ of the lowest energy conformation. Geometry optimization with the density functional theory (DFT) method for $\mathbf{2}$ was conducted using the B3LYP/6-31G+ level of theory (Figure 2b). The calculated distances of $\mathrm{H}-1 \mathrm{~b} / \mathrm{H}-4 \mathrm{~b}, \mathrm{H}-1 \mathrm{~b} / \mathrm{H}-8, \mathrm{H}-2 \mathrm{a} / \mathrm{Me}-19$, and $\mathrm{H}-4 \mathrm{a} / \mathrm{H}-7$ for 2 were $3.1,2.9,2.5$, and $3.1 \AA$, respectively. Thus, this model satisfied all of the key NOEs observed for 1 . The dihedral angles for $\mathrm{H}-2 \mathrm{~b} / \mathrm{H}-3$ and $\mathrm{H}-7 / \mathrm{H}-8$ in 2 were $-67.8^{\circ}$ and $105.8^{\circ}$, respectively. Based on the Karplus equation, ${ }^{[10]}$ the coupling constants of $\mathrm{H}-2 \mathrm{~b} / \mathrm{H}-3$ and $\mathrm{H}-7 / \mathrm{H}-8$ in 2 were estimated to be $0-2 \mathrm{~Hz}$, which coincided with those observed in $\mathbf{1}(\sim 0$ and $1.7 \mathrm{~Hz}$, respectively). For the above reason, the relative stereochemistry of the tricyclic $\gamma$-diketone portion of $\mathbf{1}$ was determined to be as shown for the model compound $\mathbf{2}$ in Figure 2.

The relative stereochemistry around the cyclopentane ring in 1 was also determined by NOE experiments and coupling constant analysis (Figure 3). NOEs were observed for $\mathrm{H}-11 \mathrm{a} / \mathrm{H}$ 14, H-14/H-17, H-17/Me-21, H-12a/Me-21, H-16a/H-22a, and $\mathrm{Me}-18 / \mathrm{H}-20$. These data strongly indicated that $\mathrm{H}-12, \mathrm{H}-14, \mathrm{H}-$ 17 , and Me-21 are oriented in the one face, and Me-18 and $\mathrm{H}-20$ are oriented in the other face of the cyclopentane ring. As a result, the relative stereochemistry of the cyclopentane ring part in 1 was identical to those of typical 9,11-secosteroids. ${ }^{[1,12]}$

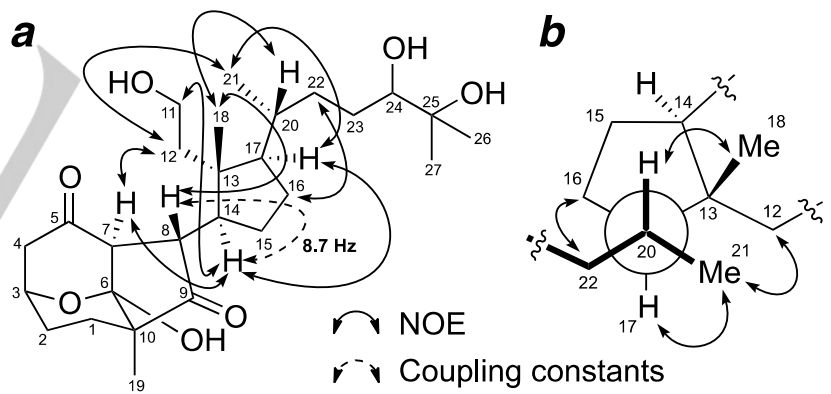

Figure 3. (a) Relative stereochemistry around the cyclopentane ring of 1 determined by $1 \mathrm{D}$ and 2D-NMR analysis (solid arrows, selected NOE correlations; dashed arrows, coupling constants). (b) A Newman projection with a view along the C20-C17-bond.

The relative stereochemistry between the tricyclic structure and cyclopentane ring part in $\mathbf{1}$ was also determined based on a detailed NMR analysis. While the C-8-C-14 $\mathrm{sp}^{3}-\mathrm{sp}^{3}$ bond is able to freely rotate, the large magnitude of $J_{8,14}=8.7 \mathrm{~Hz}$ indicated that $\mathrm{H}-8$ is positioned anti-periplanar to $\mathrm{H}-14$. NOEs were observed for $\mathrm{H}-7 / \mathrm{H}-14, \mathrm{H}-7 / \mathrm{H}-12$, and $\mathrm{H}-8 / \mathrm{Me}-18$. These results suggested that $\mathrm{H}-7, \mathrm{H}-12$, and $\mathrm{H}-14$ are oriented in the $\alpha$-face, and $\mathrm{H}-8$ and $\mathrm{Me}-18$ are oriented in $\beta$-face of the cyclopentane ring. Thus, the relative stereochemistry of $\mathbf{1}$ except for the oxymethine carbon C-24 was established to be as shown in Figure 3 . 
a

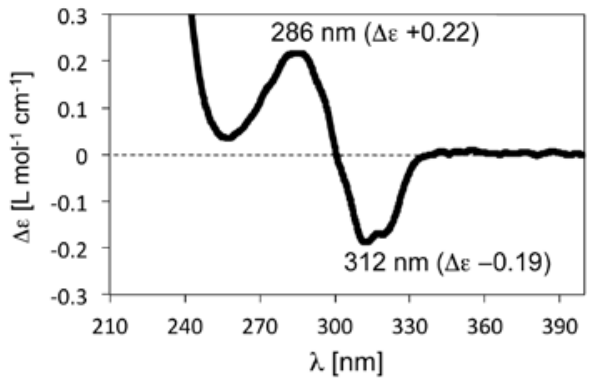

$\boldsymbol{b}$

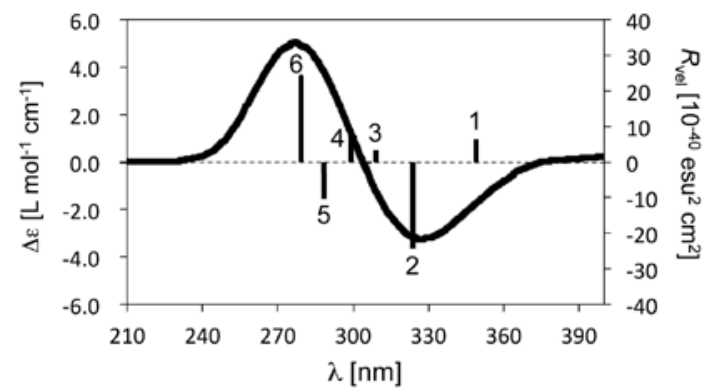

Figure 4. (a) Experimental ECD spectrum of 1 measured in $\mathrm{MeOH}$ at 0.73 $\mathrm{mM}$. (b) Calculated ECD data for the model compound 2 at the PBEPBE/6$311 \mathrm{G}++(\mathrm{d}, \mathrm{p})$ level of theory in implicit solvent model (CPCM, MeOH) (solid line, left scale). Six first excited states for 2 were shown in solid bars (right scale).

To determine the absolute stereochemistry of 1 , the experimental electronic circular dichroism (ECD) spectrum of 1 was compared with the calculated ECD data for the model compound 2 (Figure 4). ${ }^{[13]}$ The ECD spectrum of 1 showed a negative first Cotton effect at $312 \mathrm{~nm}(\Delta \varepsilon-0.19)$ and a positive second Cotton effect at $286 \mathrm{~nm}(\Delta \varepsilon+0.22)$. The calculated ECD spectrum for 2 at the PBEPBE/6-311G++(d,p) level of theory in implicit solvation model $\left(\mathrm{CPCM}^{[14]}, \mathrm{MeOH}\right)$ also had a negative ECD peak at $327 \mathrm{~nm}(\Delta \varepsilon \square-3.3)$ and a positive ECD peak at 277 $\mathrm{nm}(\Delta \varepsilon+5.0)$, which reproduced the signs of the experimental Cotton effects. As inferred from the molecular orbital analysis, the negative ECD band (band 2, $R_{\mathrm{vel}}-24.3$ ) was mainly ascribed to the $\mathrm{n} \rightarrow \pi^{*}$ transition of the C-9 ketone (HOMO $\left.\rightarrow \mathrm{LUMO}+1\right)$ (Figure 5). Meanwhile, slightly positive ECD bands at $309 \mathrm{~nm}$ (band 3, $R_{\text {vel }}+3.3$ ) and $299 \mathrm{~nm}$ (band 4, $R_{\text {vel }}+7.4$ ) were mainly ascribed to the $\mathrm{n} \rightarrow \pi^{*}$ transition of the C-5 ketone (HOMO-1 $\rightarrow$ LUMO and HOMO-1 $\rightarrow$ LUMO+1, respectively). In addition, the positive ECD band (band $6, R_{\text {vel }}+23.8$ ) corresponded to the transition from HOMO-2 to LUMO+1. These results suggested that the absolute configuration of the tricyclic $\gamma$-diketone part of 1 was identical to that of the model compound 2 .

Finally, compound 1 was converted to an 11,24-bis-MTPA ester (Figure S2). Through the use of a modified Mosher's method, ${ }^{[15]}$ the stereochemistry of C-24 was determined to be $R$.
For the above results, the absolute stereochemistry of $\mathbf{1}$ was completely established.
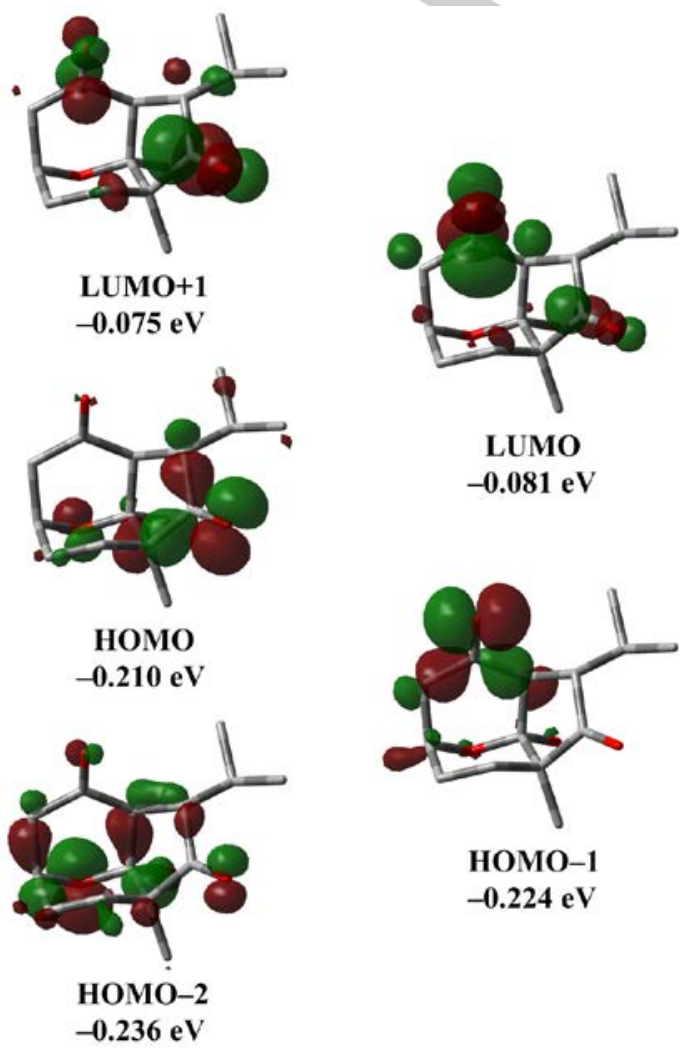

HOMO-1

$-0.224 \mathrm{eV}$

Figure 5. Molecular orbitals involved in the $n \rightarrow \pi^{*}$ transition of the C-5 and C-9 ketones in the model compound 2.

A biosynthetic pathway for the tricyclic $\gamma$-diketone structure of 1 was proposed, as shown in Scheme 1. Due to the structural similarity of the cyclopentane ring and the side-chain part of $\mathbf{1}$ with those of known 9,11-secosteroids, cholest-7-en-3S,5R,6Rtriol [16] was assumed to be a biosynthetic precursor of 1 . Oxidative cleavage of the $\mathrm{C}-9-\mathrm{C}-11$ bond and oxidation of the C-6 hydroxyl group would give 1,4-diketone 3. The $\alpha$-ketol rearrangement ${ }^{[17]}$ in $\mathbf{3}$ would lead to the formation of the C6C10 bond to give $\alpha, \beta$-unsaturated ketone 4 . The vinylogous $\alpha$ ketol rearrangement in 4 might form the C-5-C-7 bond, and subsequent enolization at the C-9 ketone would afford enol $\mathbf{5}$. Finally, protonation at C-8 and intramolecular acetalization of $\mathbf{5}$ would afford the tricyclic $\gamma$-diketone structure of 1 . The stereochemistry of the methine carbon at C-8 in general steroids is opposite to that in 1. However, protonation at C-8 in $\mathbf{5}$ might occur to give priority to the thermodynamically stable exosubstituent $8 \mathrm{~S}$ isomer. 


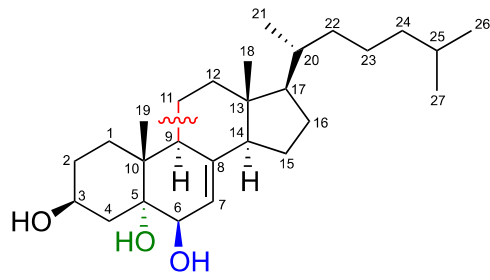

Cholest-7-en-3S,5R,6R-triol

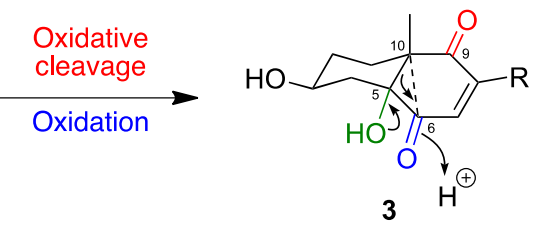

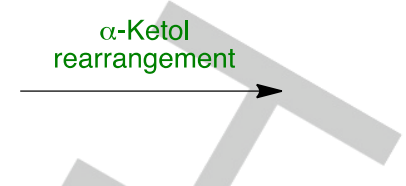

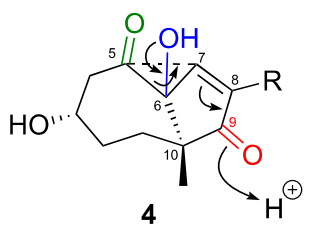
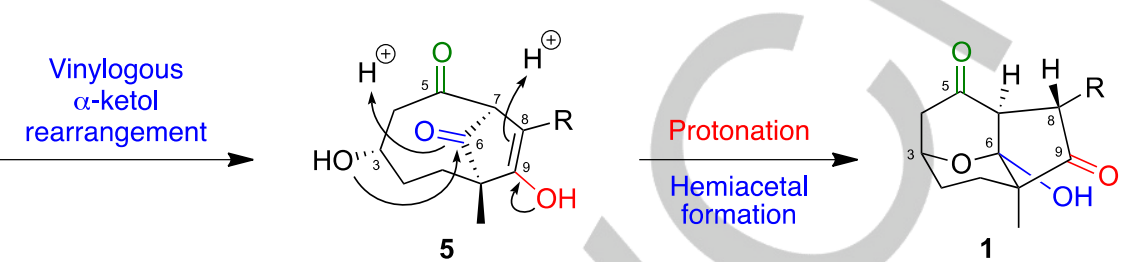

Scheme 1. Proposed biosynthetic pathway for the tricyclic $\gamma$-diketone structure of 1.

In summary, the structure and bioactivity of aplysiasecosterol A (1), a 9,11-secosteroid with a novel tricyclic $\gamma$-diketone structure, was established. Structurally and functionally diverse secosteroids have been discovered from both terrestrial and marine origin, which include 5,6-. 8,9-, 8,14-, $9,10-, 9,11-$, and 13,17-secosteroids. ${ }^{[12]}$ To the best of our knowledge, however, there are no examples that have similar tricyclic ring systems like 1. Further biological and biosynthetic studies on aplysiasecosterol A (1) are in progress.

Keywords: marine natural products $\bullet$ isolation and structure determination • electronic circular dichroism (ECD) $\bullet \alpha$-ketol rearrangement $\bullet$ biosynthesis

[1] T. E. Thompson, Biology of opisthobranch molluscs, Vol. 1. The Ray Society, London (1976).

[2] a) M. Kita, H. Kigoshi, in Handbook of Anticancer Drugs from Marine Origin, (Ed. S. K. Kim), Springer International Publishing Switzerland 2015, pp. 701-740.

[3] G. R. Pettit, in International Oncology Updates: Marine Anticancer Compounds in the Era of Targeted Therapies. (Eds. B. Chabner, $\mathrm{H}$ Cortes-Funes), Permanyer, Barcelona, 2009, pp. 19-50.

[4] a) K. Yamada, M. Ojika, T. Ishigaki, Y. Yoshida, Y. J. Am. Chem. Soc 1993, 115, 11020-11021; b) M. Ojika, H. Kigoshi, T. Ishigaki, I. Tsukada, T. Tsuboi, T. Ogawa, K. Yamada, J. Am. Chem. Soc. 1994, 116, 7441-7442; c) K. Yamada, M. Ojika, H. Kigoshi, K. Suenaga, Nat. Prod. Rep. 2009, 26, 27-43. 


\section{COMMUNICATION}

A new cytotoxic 9,11-secosteroid having an unprecedented tricyclic $\gamma$ diketone structure, aplysiasecosterol A (1), was isolated from the sea hare Aplysia kurodai. A biosynthetic pathway for $\mathbf{1}$ from a cholesterol was proposed, which includes twice $\alpha$ ketol rearrangement and an intramolecular acetalization.

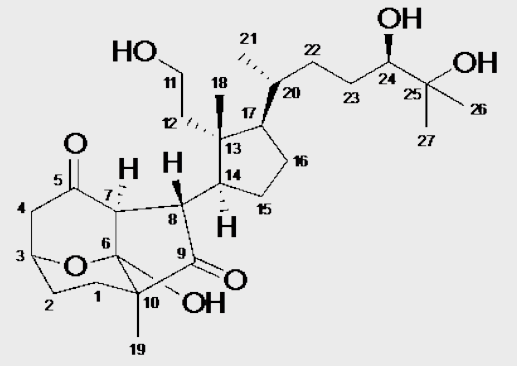

Aplysiasecosterol A (1)
Atsushi Kawamura, Masaki Kita, * and Hideo Kigoshi *

Page No. - Page No.

Aplysiasecosterol A: A 9,11-

Secosteroid with an Unprecedented Tricyclic $\gamma$-Diketone Structure from the Sea Hare Aplysia kurodai 